\title{
Jovens e adultos trabalhadores pouco escolarizados no Brasil e em Portugal: alvos da mesma lógica de conformidade*
}

Sonia Maria Rummert

Universidade Federal Fluminense, Programa de Pós-Graduação em Educação

\author{
Natália Alves \\ Universidade de Lisboa, Instituto de Educação
}

\section{Brasil e Portugal: breves considerações sobre a história recente a título de introdução}

As pesquisas que deram origem ao presente trabalho permitem apreender tanto as particularidades dos dois países, quanto as convergências que apresentam e que decorrem, entre outros aspectos, de fatores de caráter sócio-histórico e, na atualidade, da posição semiperiférica que ocupam no quadro hegemônico internacional (Santos, 1990; Stoer \& Araújo, 1992).

No âmbito da educação de jovens e adultos, podemos identificar, ao longo do século XX, convergências que não qualificam positivamente as políticas empreendidas nos dois países. Na realidade, a falta de um estatuto social, político e pedagógico para essa modalidade de ensino, a baixa taxa de escolarização da população jovem e adulta e os elevados índices de analfabetismo constituem características comuns ao Brasil e a Portugal ao longo do século XX e ainda se fazem presentes na atualidade.

* Este trabalho foi realizado no âmbito de pesquisas apoiadas pelo CNPq e pela CAPES, no Brasil, e pela FCT, em Portugal.
Outro ponto comum a destacar consiste na eficácia reduzida das medidas de combate ao analfabetismo, ao longo de quase todo o século passado, derivada tanto dos modelos tópicos, emergenciais e descontínuos de campanhas e programas adotados, quanto da ausência de um ambiente sociocultural estimulante e compatível com a real valorização dos saberes escolares, o que constitui fator indispensável à efetiva elevação dos níveis de letramento nas diferentes áreas do conhecimento. A ressaltar ainda, brevemente, a ênfase conferida pelos intelectuais orgânicos das forças dominantes em vozes uníssonas com o discurso hegemônico internacional, a relação linear entre o baixo grau de desenvolvimento dos dois países e a pouca ou nenhuma escolaridade, por ele supostamente responsável.

A análise dessas convergências brevemente enunciadas permite-nos realçar, inicialmente, um traço constante: "o caráter marginal sempre atribuído à educação de jovens e adultos da classe trabalhadora, mesmo quando as políticas e os discursos dominantes aparentemente a valorizavam, como ainda ocorre" (Canário \& Rummert, 2009). 
Embora não seja objetivo deste trabalho proceder à análise da gênese dessa problemática, apresentamos breves considerações e alguns indicadores relativos a tal quadro, visando expor, sucintamente, traços do panorama educativo convergente. Procurar-se-á também evidenciar que a questão da escolaridade da população brasileira e portuguesa deve ser compreendida como expressão de um complexo conjunto de características socioculturais, políticas e econômicas que, de formas diferenciadas, colocam ambos os países em posições diversas, mas de subalternidade no quadro hegemônico internacional, o que repercute em suas políticas educacionais.

Brasil e Portugal constituíram, no século XX, palco de longos períodos ditatoriais. Em Portugal, o "Estado Novo", ou período salazarista, estendeu-se de 1926 a 1974. No Brasil, de 1937 a 1945, a ditadura Vargas, também designada como "Estado Novo"1 e, posteriormente, a ditadura militar, de 1964 a 1985 , marcaram o país. Sob a égide do autoritarismo que constituiu, nos dois países, referente sociocultural estruturante, são convergentes as concepções orientadoras das políticas educacionais, no que concerne à ausência de efetivos compromissos do Estado com a plena escolarização de seus contingentes populacionais. No Estado Novo brasileiro, apenas $21 \%$ da população entre 5 e 19 anos frequentava a escola, conforme dados de 1940, informados pelo Instituto Brasileiro de Geografia e Estatística (Brasil, IBGE, 2009b). Tal quadro, mesmo findo o primeiro período ditatorial, pouco se alterou, passando, na década de 1960, para 31\% (idem). Do mesmo modo, a ditadura salazarista pouco fez, efetivamente, visando ao aumento da escolaridade da população. Apesar de na década de 1960 se registar, pela primeira vez, amplo acesso das crianças à escola, tal escolarização era "curta e incipiente" (Candeias \& Simões, 1999, p. 174). ${ }^{2}$ Para

${ }^{1}$ Análise comparativa sobre o Estado Novo no Brasil e em Portugal pode ser encontrada em Martinho e Pinto (2007).

2 Não nos deteremos na abordagem dos instrumentos legais que, desde o século XIX, foram promulgados com o objetivo proclamado de reverter o quadro educacional.
Lima, trata-se de uma população "a quem, historicamente e maioritariamente, foi negado o acesso a um processo de escolarização sistemático e relativamente prolongado" (Lima, 2004, p. 20), tal como verificado no Brasil.

As similitudes permanecem no que concerne especificamente aos índices de analfabetismo. ${ }^{3}$ Enquanto parte expressiva dos países da Europa já havia, na primeira metade do século XX, alcançado a universalização da educação, registrando, em 1950, um índice de $98 \%{ }^{4}$ de sua população alfabetizada, Portugal apresentava, tão somente, uma taxa de alfabetização de 55\%. No caso do Brasil, segundo dados da UNESCO/ONU, citados pelo IBGE Teen (2009), na mesma década, enquanto a taxa média de analfabetismo na América Latina e Caribe era de $42 \%$, o país apresentava $50,3 \%$ de sua população na condição de analfabeta (Brasil, IBGE, 2009a).

Esse quadro educacional similar organiza-se a partir de perspectivas de política econômica e de industrialização particulares. Por um lado, no Brasil, registra-se um significativo avanço em relação ao incipiente parque industrial português, por outro, são expressivas as convergências, por exemplo, no que tange às teses relativas à prioridade a ser dada ao crescimento econômico para a posterior distribuição da riqueza, traduzidas na máxima "crescer para depois distribuir". ${ }^{5}$

Essa lógica de política econômica, altamente concentradora de riqueza material e simbólica, expressou-se, no âmbito da educação, em um quadro de escassez da oferta de ensino público à população em idade escolar, que impôs à classe trabalhadora um

3 Atemo-nos, aqui, à terminologia que orienta os dados estatísticos.

${ }^{4}$ Alemanha, Áustria, Bélgica, Escócia, Dinamarca, Finlândia, França, Holanda, Hungria, Inglaterra, Irlanda, País de Gales, Noruega, Suécia, Suíça. Conforme dados de Johansson, citado por Graff (1991, p. 375), apud Candeias e Simões (1999, p. 168).

5 Sobre o Brasil, ver, entre outros, Gonçalves (2003). Sobre Portugal, particularmente até 1974, ver, por exemplo, Silva (1982). 
baixo grau de escolarização, o qual perdurou durante quase todo o século. Segundo o Instituto Nacional de Estatística (INE), Portugal registra, no Censo de 1981, 27,4\% da população ainda sem nenhum nível de escolaridade e $47,6 \%$ com apenas o $1^{\circ}$ ciclo do ensino básico (Portugal, INE, 2001, p. 5). No Brasil, chegase ao ano de 1978 com apenas $58 \%$ da população em idade escolar matriculada nos estabelecimentos de ensino básico públicos e privados, e com uma taxa de analfabetismo de 25,41\% (Brasil, IBGE, 2009b) no ano de 1980.

Marcados por essa lacuna no âmbito da escolarização, gerada pela lógica do padrão socioeconômico dominante, bem como pelas relações construídas nos complexos universos societários dos dois países com a cultura letrada, Brasil e Portugal enfrentam, ao longo do século XX, as contradições inerentes à passagem da condição de sociedades tradicionais, de forte caráter rural, para o paradigma urbano-industrial. As peculiaridades desse processo não podem ser aqui analisadas. Porém, é necessário registar que, nesse período, as forças dominantes, em consonância com a divisão internacional do trabalho, optaram por desenvolver um processo de industrialização no qual predominavam os baixos salários e uma força de trabalho pouco qualificada, visto que a formação não constituía fator relevante para o processo produtivo. Pode-se afirmar, grosso modo, que as duas nações optaram "por uma espécie de taylorismo sem fordismo" (Mendonça \& Fontes, 1991, p. 131), que encontrava no êxodo rural a reserva de mão de obra, com baixa ou nenhuma qualificação, necessária ao padrão de especialização industrial em curso. Brasil e Portugal enfrentam, assim, a questão de como modernizar as suas sociedades, orientados pelas referências ao moderno, ao novo, ao futuro, derivadas da crença no projeto desenvolvimentista.

Nas últimas décadas do século XX, importantes mudanças ocorrem nos dois países. Em Portugal, a Revolução dos Cravos, de 25 de abril de 1974, assinalou a ruptura com o regime ditatorial. Verifica-se, então, o ingresso em um processo de modernização implantado segundo os padrões dominantes na Europa, com a ampliação das políticas sociais e dos serviços públicos, o estabelecimento de padrões contratuais para as relações de trabalho, a criação de complementos salariais e o estabelecimento do salário mínimo nacional,já em vigor no Brasil desde a Ditadura Vargas.

No Brasil, em 1985, a partir de um processo negociado e de acordo com as novas diretrizes para os países da América Latina - definidas, entre outros agentes, pelos organismos internacionais -, finda a ditadura militar e instaura-se a chamada Nova República. O país procura afirmar-se como economia capitalista monopolista dependente no contexto mundial, coadunado com as bases socioeconômicas da cada vez mais intensa internacionalização do capital e da mundialização da economia.

Por seu turno, Portugal é marcado por alterações profundas no que concerne a seu projeto de país, a partir do momento em que inicia o processo de adesão à Comunidade Europeia, que se concretizará em 1986. No entanto, sua posição subordinada em relação aos países do núcleo orgânico do capital não se altera. Observa-se, então, o desenvolvimento de uma economia de mercado aberta e receptiva ao investimento estrangeiro, mas que continua incipiente no plano industrial. Na década de 1990, o Brasil, a partir da liberalização das importações e ante a introdução de novos paradigmas tecnológicos e de organização produtiva, inaugura uma nova fase de industrialização. Essa nova fase passou, por um lado, a exigir uma diversidade de ações inovadoras e, por outro, colocou em evidência a fragilidade da política industrial do país, bem como das suas políticas educacionais agora carecendo de ajustes ao novo cenário mundial.

A centralidade agora atribuída à educação nos discursos das forças dominantes - e partilhada, de formas diferenciadas, nas classes trabalhadoras (Rummert, 2000, 2004) - não adquire suficiente materialidade nas políticas de garantia de acesso e permanência na escola, nas duas últimas décadas do século XX, no Brasil e em Portugal. Tal fato, aparentemente paradoxal, pode ser constatado por alguns indicadores como, por exemplo, o referente às taxas de analfabetismo. Em Portugal, registrava-se, em 1991, $11 \%$ de analfabetos com 10 anos ou mais de idade 
(Portugal, INE, 1991) e, no Brasil, em 1992, havia ainda $16,4 \%$ de analfabetos na mesma faixa etária (Brasil, IBGE, 2009b). Já no novo milênio, em 2001, Portugal contava ainda com 9\% (Portugal, INE, 2001) de sua população com 10 anos ou mais de idade constituída por analfabetos, e o Brasil ainda apresentava uma taxa de $11,4 \%$ da população na mesma situação (Brasil, IBGE, 2009b). Quanto aos níveis de escolaridade, os dados também não se apresentavam promissores. Embora os dez anos que separam os indicadores aqui referidos indiquem que Portugal avança no período em relação ao Brasil (possivelmente devido ao ingresso na UE), ainda é bastante baixo o nível de escolaridade da população do país: em 1991, 72,6\% possuía somente até seis anos de escolaridade, índice que se eleva para $88 \%$ em $2001 .{ }^{6}$ No caso brasileiro, $50,7 \%$ da população com 15 ou mais anos de idade possuía até sete anos de estudo, ${ }^{7}$ em 1992. No decorrer dos dez anos seguintes, o aumento da escolaridade avançou timidamente no Brasil, registrando-se ainda 43,75\% do mesmo grupo populacional com, no máximo, até sete anos de estudo, em 2001.

Os dois países ingressam no século XXI em situação de forte dependência político-econômica e sociocultural derivada do aprofundamento da tendência de globalização da economia. Nesse novo estágio de acumulação capitalista, é atribuído, em nível mundial, um estatuto normativo às teses em defesa da prioridade a ser concedida ao aumento de competitividade. Para tentar fazer frente às suas dificuldades estruturais em assumir posições mais competitivas no cenário mundial, Brasil e Portugal, sob o jugo dos fundamentos do padrão de acumulação flexível (Harvey, 1992), passam a organizar-se em torno da tríade da desregulamentação, da privatização e da abertura comercial, ideias consagradas por várias organizações multilaterais e que se transformaram no núcleo inexorável das bases teórico-práticas do incontornável ajuste econômico.

${ }^{6}$ Dados calculados pelas autoras a partir dos Censos de 1991 e 2001 de Portugal, INE.

${ }^{7}$ Dados calculados pelas autoras a partir de Brasil, IBGE, Séries estatísticas e séries históricas (2009).
Essas ideias-força, transpostas para o conjunto das relações societárias - e, por consequência, para a educação - são incorporadas como premissas inquestionáveis às teses da teoria do capital humano, agora revisitadas sob a égide da nova lógica empresarial e gestionária. Em nível mundial, e em particular nos países semiperiféricos e periféricos, a educação é alçada à condição de luz, com o poder de iluminar os tempos sombrios decorrentes das necessárias medidas de ajustamento econômico. Trata-se, portanto, segundo documento publicado pela Task Force on Higher Education and Society, constituída pelo Banco Mundial e pela Organização das Nações Unidas para a Educação, a Ciência e a Cultura (UNESCO), de acender a luz da educação. Segundo os dois organismos internacionais,

\begin{abstract}
Conhecimento é como a luz. Sem peso e intangível, ele pode facilmente viajar o mundo iluminando as vidas de pessoas por toda a parte. Embora bilhões de pessoas ainda vivam na escuridão da pobreza, desnecessariamente. Em parte, pelo menos, as pessoas vivem na pobreza, porque elas não podem alcançar a chave para ligar a luz, e essa chave é chamada educação. (The Work Bank, 2000, p. 18-19)
\end{abstract}

\section{A educação flexibilizada sob a égide da privatização do conhecimento}

No contexto brevemente delineado anteriormente, ambos os países implementam políticas voltadas para a educação e formação profissional de jovens e adultos, visando reverter o quadro de baixa certificação no nível da educação básica e profissional de sua população. Essas políticas são sustentadas por dois fortes elementos argumentativos: as exigências da sociedade do conhecimento e a importância da coesão social, e subordinam-se às características e demandas do padrão de acumulação flexível, que conferem particularidades à oferta de oportunidades educacionais aos trabalhadores que permanecem vitimados pelas decorrências do processo de concentração de riqueza.

As marcas da tese da concentração de riqueza para posterior distribuição, como anteriormente assi- 
nalado, apresentam-se, embora com variações, como elementos normativos dos regimes de acumulação. Segundo Gramsci (1988) e Harvey (1992), o êxito do processo de acumulação exige a existência de uma correspondência entre as condições necessárias à produção e à reprodução da força de trabalho. É preciso que esse processo de reprodução se estenda para além dos trabalhadores imediatamente necessários, (con)formando, a partir de diferentes estratégias de disciplinamento, o conjunto de agentes sociais e econômicos, à lógica subjacente a cada uma das fases de expansão e consolidação do capital.

São as necessidades do sistema produtivo, em seus diferentes estágios, que regulam a quantidade e o tipo de oferta de oportunidades educacionais à classe trabalhadora. Ou seja, o grau e a forma da qualificação profissional, assim como as condições de acesso à educação geral, constituem, regra geral, uma construção social definida, predominantemente de acordo com os interesses dominantes. Nessa construção social, porém, não podem ser ignoradas as reivindicações das diferentes frações da classe trabalhadora. Se, por um lado, as forças dominantes difundem - pode-se dizer que com êxito - a crença na educação/formação como chave de sucesso e garantia de inclusão, por outro, não podem furtar-se a propiciar condições de acesso a oportunidades de educação/formação, mesmo que na forma de meros simulacros. É necessário, portanto, não ignorar o fato de que a manutenção das bases materiais e ideológicas do processo de acumulação não constitui um processo histórico destituído de contradições e conflitos. Ao contrário, é marcado por tensões e lutas inerentes a todas as manifestações das correlações de forças intrínsecas à permanente construção e manutenção da hegemonia, sobretudo em sociedades profundamente desiguais, como as que analisamos.

Os aspectos aqui sumariamente referidos apontam para a importância de uma compreensão mais alargada de políticas aparentemente destinadas a democratizar o acesso à educação para os jovens e adultos. Na realidade, a ênfase no leque de oportunidades, que gradativamente será colocado à disposição dos trabalhadores, nos dois países, a partir de meados da primeira década deste século, encobre um processo, identificado por Gramsci (2000), de multiplicação artificial de ofertas educativas visando manter a hegemonia das forças dominantes, atendendo, concomitantemente, às sempre renovadas exigências dos processos de acumulação.

Num quadro de desemprego estrutural de massas, de precarização dos vínculos laborais, do refluxo das bases keynesianas do chamado Welfare State - conhecido de forma mais próxima por Portugal do que pelo Brasil -, o aumento da concessão de diplomas passou a constituir a estratégia fundamental de manutenção da hegemonia e de controle social.

Os aspectos já apontados reportam ao fato de que se vive, atualmente, uma nova fase de mundialização e internacionalização da economia, em que se potencializam os riscos de conflitos sociais e se agudizam as características da pobreza, o que coloca em risco a estabilidade e a administração do capital. Nesse quadro, os Estados situados na semiperiferia veem ampliadas as condições de dependência e de subordinação externas na atual divisão internacional do trabalho (Arrighi, 1997), em consequência de decisões político-econômicas fortemente influenciadas pelos organismos de regulação supranacionais. São precisamente esses organismos que, de uma forma recorrente, emitem recomendações no sentido de que os países periféricos e semiperiféricos ampliem a oferta de educação/formação destinada à classe trabalhadora.

Para os organismos internacionais, trata-se de criar mecanismos sociais destinados a controlar os conflitos e assegurar a coesão social. O estado de latente tensão social é reconhecido, por exemplo, pelo Conselho da Europa: "Todas as sociedades têm que viver com tensões e pressões provocadas por divisões existentes ou potenciais. Por exemplo, verificam-se em todas as sociedades disparidades de riquezas entre os indivíduos; quando essas disparidades são excessivas ou tendem a aumentar, a coesão é ameaçada" (Comitê Europeu para a Coesão Social, 2004, p. 3).

As forças dominantes brasileiras também reconhecem a importância atual da educação, seja no nível dos novos requerimentos do núcleo central dos 
processos produtivos, seja no âmbito do controle social. Ao tratar de suas próprias iniciativas no âmbito da educação dos trabalhadores, a Confederação Nacional da Indústria (CNI) ressalta que "A educação é uma das vertentes fundamentais para o crescimento da economia, seja pelo efeito direto sobre a melhoria da produtividade do trabalho - formação de trabalhadores mais eficientes, capital humano - seja pelo aumento da capacidade do país de absorção e geração de novas tecnologias" (CNI, 2007, p.10).

Ainda no final do século passado, o empresariado brasileiro ressaltava a importância da questão educacional na construção "de um país dotado de melhores condições para desenvolver o seu negócio" (Iochpe,1998). A empresária Iochpe evidenciava ainda a intencionalidade interessada do capital, ao defender que as empresas devem assumir um rosto mais social: "Cai-se, portanto, na lei de fogo da responsabilidade social montada por Keith Davis: 'a longo prazo, quem não usa o poder de uma maneira que a sociedade considera responsável, tenderá a perder esse poder"' (idem). A síntese dessa lógica hegemônica, em ambos os países, é-nos apresentada, de uma forma inequívoca, pelo Conselho da Europa: "o que é bom para a coesão social é bom para os negócios" (Comitê Europeu para a Coesão Social, 2004, p.11).

É nesse contexto que a aprendizagem ao longo da vida - expressão cunhada e disseminada em declarações e eventos internacionais patrocinados por organismos supranacionais, como o Banco Mundial e a UNESCO, na década de 1990 - se apresenta como a resposta à atual fase capitalista de acumulação flexível. A aprendizagem ao longo da vida trata a nova fase capitalista de forma naturalizada e evoca a adaptação/preparação dos indivíduos como forma de responder ao novo quadro hegemônico internacional. Trata-se, assim, de promover a adaptação funcional dos sujeitos e da educação à economia, difundindo a crença de que os problemas de inserção ou permanência no mercado de trabalho são decorrentes da pouca ou inadequada formação dos trabalhadores. Essa perspectiva é justificada pela necessidade de maior qualificação para lidar com o mundo do trabalho, imposta pela dita complexa sociedade da informação ou sociedade do conhecimento.

Para a CNI, o capital humano constitui o "principal ativo das empresas, é formado pelo conjunto de habilidades que as pessoas detêm, adquiridas por meio de processos educativos, treinamento ou da experiência" (CNI, 2007, p. 22). Essa lógica, que universaliza as bases do léxico dominante sobre a educação, sublinha o fato de que "As chamadas competências básicas, formadas pela educação básica e a continuada, são condição para o desenvolvimento das demais competências, inclusive as profissionais, na medida em que possibilitam continuar aprendendo e aperfeiçoando-se durante toda a vida" (idem, p. 22).

$\mathrm{Na}$ realidade, de acordo com Canário (2001), a análise das intencionalidades subjacentes às teses de formulações como as citadas permite ampliar a expressão educação ao longo da vida, desvelandolhe o caráter de educação ao longo da vida produtiva para o Capital.

A lógica que preside a ênfase na educação/formação assegura que, diante do caráter restritivo do mercado de trabalho na atualidade, cabe aos indivíduos adquirir ou ampliar competências e habilidades para a empregabilidade (Alves, 2008), justificando-se a aprendizagem ao longo da vida pela necessidade de introjeção de uma atitude competitiva, por todos os indivíduos e pelas sociedades agora diluídas em amplos mercados. Mas essa lógica assegura também que, mesmo diante da inexistência de postos de trabalho para todos, é necessário procurar alternativas de sobrevivência (autogeração de rendimento, empreendedorismo), justificando-se a importância da aprendizagem ao longo da vida pela necessidade de desenvolver uma atitude empreendedora e pró-ativa.

Constrói-se, assim, uma concepção de mundo (Gramsci, 1999) ancorada num discurso que legitima as reformas dos Estados nacionais, estruturadas a partir dos interesses das grandes corporações, mediados pela atuação dos organismos internacionais como a OCDE, ${ }^{8}$

\footnotetext{
${ }^{8}$ Portugal é país membro da OCDE (Organização para
} Cooperação e Desenvolvimento Econômico) desde 1961. O Brasil, 
o Banco Mundial, o Banco Interamericano de Desenvolvimento (BID), o Fundo Monetário Internacional (FMI) e a UNESCO. Esses organismos vinculam a educação, a modernização social, a democracia e a cidadania aos interesses do atual padrão de acumulação, "através de programas de cooperação técnica, de apoio à investigação e ao desenvolvimento, [que] sugerem ou impõem, de modo uniformizado, diagnósticos, técnicas e soluções" (Canário, 1999, p. 30). ${ }^{9}$

Esse quadro toma contornos particulares quando consideramos que tanto Portugal quanto o Brasil se inscrevem, embora em patamaraes diferenciados, na atual configuração da divisão internacional do trabalho, prioritariamente como lócus de transferência, cópia e consumo de ciência e tecnologia, e não pela sua produção autônoma. Tal fato faz que as medidas adotadas, a partir das influências já referidas, apresentem como horizonte o favorecimento dos processos de adaptação desses países aos padrões de concorrência internacional na economia globalizada, numa suposta situação favorável de competitividade. Pretende-se, assim, que Portugal atinja uma situação semelhante à dos demais países da União Europeia e que contribua para a concretização da Estratégia de Lisboa: transformar a UE “na economia do conhecimento mais competitiva e dinâmica do mundo, capaz de garantir um desenvolvimento económico sustentável, com mais e melhores postos de trabalho e uma maior coesão social" (Conselho Europeu de Lisboa, março de 2000). Objetivos similares, no plano discursivo, norteiam as políticas econômicas - e educacionais - no caso brasileiro.

No que se refere à educação das diferentes frações da classe trabalhadora, registraram-se, no Brasil e em Portugal, na primeira década deste século, significativas

atualmente, é considerado país associado, sendo signatário de acordos em diferentes áreas, entre elas o âmbito da educação.

${ }^{9}$ A influência desses organismos na formulação de políticas educacionais em Portugal e no Brasil é abordada em diferentes filiações teóricas. Como exemplo no caso de Portugal, podemos citar: Barroso (2006); Canário (1999, 2001, 2004); Estrela e Teodoro (2007); Teodoro (2001). No caso brasileiro, por exemplo: Leher (2008); Silva Jr. (2006); Siqueira (2003, 2004). mudanças na forma e no conteúdo das ofertas educativas que permanecem, porém, subordinadas à lógica do padrão de acumulação flexível. Tais mudanças constituem uma expressão de formas cada vez mais refinadas de manutenção, sob novas bases, das condições de subalternidade que não estão em causa, seja no plano nacional, seja no quadro hegemônico internacional. Esse conjunto de iniciativas é marcado por heterogeneidades compatíveis com as características da atual fase de acumulação, nomeada como era pós-industrial ou, mais correntemente, como sociedade do conhecimento ou da informação. A análise de seu teor corrobora o fato de que a base dos regimes de acumulação está ancorada na distribuição desigual dos bens materiais e simbólicos, entre os quais se destaca a educação.

Na realidade, o discurso defensor do universalismo da educação básica para os jovens e adultos com baixa escolarização materializa-se em políticas de governo que, na maior parte da vezes, conferem o direito de acesso a certificações de escolaridade que legitimam simulacros de educação, enraizados numa lógica compensatória. Em detrimento do efetivo acesso universal ao conhecimento, essas políticas aprofundam e legitimam desigualdades, sob a aparente democratização de oportunidades, o que só pode ser desvelado quando analisamos as formas diversificadas de manutenção do quadro de privatização do conhecimento - que em sua plenitude só é acessível a poucos, a partir de sua origem de classe - associado aos processos de divisão social do trabalho vigentes, de modo coadunado, com os quadros de hegemonia nacional e internacional.

Como exemplos do que foi antes afirmado, destacamos, neste artigo, o Programa Nacional de Inclusão de Jovens (ProJovem), no Brasil, e o Programa Novas Oportunidades (PNO), em Portugal, cujas lógicas de concepção e implementação materializam processos de distribuição desigual de condições de acesso ao conhecimento científico e tecnológico, paradoxalmente apresentado como essencial para assegurar a todos condições equânimes para usufruir dos supostos benefícios dos novos paradigmas societários, centrados nas novas formas de organização produtiva, na lógica de mercado e na competitividade. 
Antes de proceder à análise dos programas referidos, deve-se fazer breve menção a outra política de governo, o Programa Nacional de Integração da Educação Profissional com a Educação Básica na Modalidade de Educação de Jovens e Adultos (PROEJA), o qual não será abordado em virtude dos objetivos e limites do presente trabalho, que não permitem a análise de suas particularidades. Cabe, entretanto, assinalar alguns aspectos que, por um lado, permitem compreender o PROEJA como uma iniciativa que apresenta possibilidades de constituir avanços significativos no âmbito teórico-metodológico da educação de jovens e adultos, mas, por outro, o filiam a características similares às das demais políticas atualmente em curso, como aqui abordado.

As positividades do Programa residem, sobretudo, na perspectiva de integração da educação profissional à educação básica, que pode ser implementada, embora também seja abrigada na proposta a forma concomitante. Outro aspecto a ressaltar consiste no fato de que sua execução é atribuída preferencialmente aos Institutos Federais de Educação, Ciência e Tecnologia (IFEPTs, antigos Centros Federais de Educação Tecnológica),${ }^{10}$ instituições brasileiras com larga tradição e experiência em educação profissional. Finalmente, para os fins deste trabalho, ressaltamos as ações complementares: de formação de professores para atuar no PROEJA, em nível de "pós-graduação lato sensu”, ação inédita na área, e o fomento a pesquisas específicas visando à análise e ao aperfeiçoamento do Programa.

Apesar de seus aspectos positivos, entre os quais os antes assinalados, o PROEJA se inscreve,

${ }^{10}$ Embora também sejam proponentes elegíveis o Colégio Pedro II e as secretarias de educação ou de ciência e tecnologia que são responsáveis pela educação profissional. Se a responsabilidade atribuída aos IFEPTs confere possibilidades de significativo avanço nas concepções e práticas de EJA, entretanto, é preciso ressaltar que as condições objetivas para a implementação do PROEJA nessas instituições ainda se afastam muito do que seriam efetivamente necessárias, o que compromete sensivelmente a concepção proclamada. até o momento, na mesma lógica de multiplicação de ofertas que corrobora a permanência da segmentação e diferenciação de possibilidades de maior ou menor grau de acesso ao conhecimento, que marca as ofertas educativas para os jovens e adultos trabalhadores. ${ }^{11}$

Em seguimento a essa breve apresentação, é necessário ressaltar o fato de que o PROEJA traz ainda a marca da educação de jovens e adultos: um caráter de naturalização da negação do direito à educação básica como efetivo acesso universal às bases do cohecimento científico e tecnológico. Essa naturalização explicitase, paradoxalmente, na própria estrutura montada pelo MEC para colocar em prática essa política de governo e é evidenciada , por exemplo, pela ausência de uma clara definição referente à dotação orçamentária que assegure a continuidade e a ampliação do Programa. O paradoxo aprofunda-se, se considerarmos aspectos que se complementam e derivam da falta de empenho político que se expressa na questão orçamentária.

$\mathrm{O}$ primeiro refere-se às metas de atendimento estabelecidas: conforme o Ministério da Educação, “A expectativa é abrir 60 mil matrículas com um investimento de R\$398 milhões até 2011. Em 2008, a Rede Federal de Educação Profissional, Científica e Tecnológica matriculou 9.141 alunos em cursos do PROEJA, num investimento de R \$20,9 milhões. Com a adesão dos sistemas estaduais e municipais, a meta estimada de matrículas para 2009 é de 40 mil" (Brasil, Ministé-

${ }^{11}$ As ofertas de conclusão dividem-se em seis possibilidades: “1- Educação profissional técnica integrada ao ensino médio na modalidade de educação de jovens e adultos; 2- Educação profissional técnica concomitante ao ensino médio na modalidade de educação de jovens e adultos; 3- Formação inicial e continuada ou qualificação profissional integrada ao ensino fundamental na modalidade de educação de jovens e adultos; 4- Formação inicial e continuada ou qualificação profissional concomitante ao ensino fundamental na modalidade de educação de jovens e adultos; 5- Formação inicial e continuada ou qualificação profissional integrada ao ensino médio na modalidade de educação de jovens e adultos; 6- Formação inicial e continuada ou qualificação profissional concomitante ao ensino médio na modalidade de educação de jovens e adultos" (Brasil, Ministério da Educação/SETEC, 2010). 
rio da Educação/SETEC, 2009), quantitativo bastante incipiente diante dos índices de baixa escolaridade de jovens e adultos no país, já apresentados. O segundo aspecto remete ao fato de que, em decorrência da falta de condições objetivas para a implemetação alargada do Programa, as poucas vagas oferecidas não são alvo de suficiente divulgação, acarretando, com frequência, procura inferior à oferta, fato que também decorre, muitas vezes, de inadequação de horários, impedindo a matrícula daqueles que, de formas diferenciadas, estão comprometidos com situações de trabalho. A essas questões soma-se a predominante ausência de uma proposta político-pedagógica efetivamente centrada nas complexas e fundamentais relações entre a técnica, a tecnologia, a ciência e a educação. Tal fato repercute na formação profissional centrada no como fazer imediato, no pragmatismo da formação - tanto naquela ofertada aos alunos do Programa, quanto na qualificação docente nos cursos de pós-graduação já referidos - que se afasta substantivamente da formação integral.

\section{O Programa Novas Oportunidades e o Programa Nacional de Inclusão de Jovens: duas faces de uma mesma lógica ${ }^{12}$}

É na convergência entre a persistência dos problemas estruturais e a fuga de seu efetivo enfrentamento por sólidas políticas públicas que se situam tanto o PNO quanto o ProJovem, ambos constituindo expressão de um novo ciclo para a educação de jovens

${ }^{12}$ A presente análise baseia-se no conjunto de documentos oficiais referentes aos Programas abordados. Tal procedimento metodológico não elide o fato de que, no bojo dos referidos programas, são desenvolvidas, por diferentes agências e agentes, ações que repercutem na vida de vários trabalhadores que a eles têm acesso, a partir de diferentes graus de positividade derivados, em larga medida, da ausência de políticas educacionais e culturais de largo e democrático alcance para todos. O que se pretende ressaltar no presente estudo é que as políticas em causa não transformam a vida do trabalhador social, sempre subsumido à lógica do modo de produção em que se situa a gênese da distribuição diferencial do conhecimento. e adultos, iniciado na primeira metade da primeira década do século XXI nos dois países.

O PNO, lançado em Portugal em 2005, propõe qualificar e certificar de forma acelerada cerca de um milhão dos integrantes da população economicamente ativa até 2010 , recorrendo a procedimentos supostamente inovadores, como o Reconhecimento, Validação e Certificação de Competências, ${ }^{13}$ e a oferta de cursos de dupla certificação (escolar e profissional) para jovens e adultos, em funcionamento em entidades públicas e privadas autorizadas, tais como escolas, empresas, autarquias e associações empresariais, associações de trabalhadores, instituições de desenvolvimento local, entre outras. Seu funcionamento concretiza-se a partir de dois eixos: o eixo Oportunidade Nova, ${ }^{14}$

13 Os primeiros Centros de Reconhecimento, Validação e Certificação de Competências datam do ano 2000, assim como a criação de novos cursos de Educação e Formação de Adultos (cursos EFA), sob a supervisão da Agência Nacional de Educação e Formação de Adultos (ANEFA), posteriormente substituída pela Direção Geral de Formação Vocacional e, a seguir, pela atual Agência Nacional para a Qualificação. O Sistema de Reconhecimento, Validação e Certificação de Competências permite que os maiores de 18 anos possam obter o reconhecimento, validação e certificação das competências (escolares, profissionais e outras) adquiridas em diferentes situações de aprendizagem (vida pessoal, social e profissional), para efeitos de atribuição de uma qualificação formal, escolar ou profissional. A certificação conferida por esse sistema contempla o nono ano do ensino básico ou o nível secundário. $\mathrm{O}$ processo de RVCC é desenvolvido atualmente nos Centros Novas Oportunidades que funcionam em estabelecimentos de ensino básico e secundário, em Centros de Formação Profissional do Instituto do Emprego e Formação Profissional (IEFP) e em outras diversas entidades formadoras acreditadas, públicas ou privadas.

${ }^{14} \mathrm{O}$ Eixo Oportunidade Nova é constituído por cursos de dupla certificação ao nível do $12^{\circ}$ ano e uma qualificação profissional de nível três, com a duração média de três anos. Os referidos cursos podem ser: cursos profissionais, organizados em módulos; cursos de aprendizagem em alternância entre as escolas e as empresas ou os cursos de ensino artístico especializado, no âmbito das artes visuais ou audiovisuais. 
para os jovens, e o eixo Nova Oportunidade, ${ }^{15}$ para os adultos.

$\mathrm{Na}$ realidade, sem abrigar novas medidas educativas, o PNO apresenta, contudo, duas novidades no país. A primeira refere-se ao estabelecimento de metas quantitativas, cujo alcance é rigidamente controlado pela Agência Nacional de Qualificação, com base em sofisticado sistema informático. A segunda consiste na consagração do $12^{\circ}$ ano (correspondente ao término do ensino secundário) como referencial mínimo para a população, quando a escolaridade obrigatória se mantinha apenas até o $9^{\circ}$ ano, o que só veio a se alterar em termos legais no ano de 2009. Com essa referência, o Programa objetiva, entre outros aspectos, elevar a escolaridade da população de modo que situe Portugal na faixa média dos países membros da OCDE.

Por suas características, o PNO constitui uma expressão da adesão portuguesa ao método aberto de coordenação, ${ }^{16}$ representa a aceitação dos objetivos e metas quantitativas definidas em nível europeu e pelos

${ }^{15}$ O Eixo Nova Oportunidade, além do Sistema Nacional de Reconhecimento, Validação e Certificação de Competências, oferece os Cursos de Educação e Formação de Adultos (Cursos EFA), com dupla certificação ao nível do $9^{\circ}$ ou do $12^{\circ}$ ano; Formações Modulares, variando de 25 a 600 horas subordinadas à oferta ao Catálogo Nacional de Qualificações e pode ser cursado de forma gradativa e flexível; e ainda vias de conclusão do ensino secundário para aqueles que precisem completar esse nível cursando ou prestando exames em até, no máximo, seis disciplinas.

${ }^{16}$ De acordo com o Europa - Glossário, o "método aberto de coordenação (MAC) foi definido enquanto instrumento da Estratégia de Lisboa (2000). O MAC representa um novo quadro de cooperação entre os Estados-Membros a favor da convergência das políticas nacionais, com vista à realização de determinados objetivos comuns. No âmbito desse método intergovernamental, os Estados-Membros são avaliados pelos outros Estados-Membros (peer pressure), competindo à Comissão unicamente uma função de vigilância. [...] O método aberto de coordenação intervém em certos domínios da competência dos Estados-Membros como o emprego, a proteção social, a inclusão social, a educação, a juventude e a formação" (site Europa - Glossário). organismos internacionais e reforça a tendência profissionalizante do sistema educativo, subordinando-o às teses da aprendizagem ao longo da vida, tal como concebida pelos organismos internacionais.

Segundo o discurso oficial, o PNO apresenta-se como "condição essencial para a afirmação de uma estratégia sustentável de crescimento económico e de coesão social". Essa perspectiva levou à criação da "Iniciativa Novas Oportunidades, que reúne um conjunto alargado de instrumentos, que visam a acelerar o ritmo de progressão dos níveis de escolarização e de qualificação profissional dos portugueses" (Portugal, Ministérios da Administração Interna, do Trabalho e Coesão Social e da Educação, 2006). Seu objetivo principal consiste em "Criar uma resposta de conclusão e certificação adaptada a indivíduos com idade igual ou superior a 18 anos, com percursos de ensino secundário incompletos, reforçando: a flexibilidade das soluções e a sua acessibilidade" (Portugal, Novas Oportunidades, 2007).

A arquitetura do Programa coaduna-se claramente com os preceitos da Declaração de Hamburgo (V CONFITEA - Declaração de Hamburgo, 1997), segundo a qual a "A educação de adultos inclui a educação formal, a educação não formal e o espectro da aprendizagem informal e incidental disponível numa sociedade multicultural, onde os estudos baseados na teoria e na prática devem ser reconhecidos" (Declaração de Hamburgo, 1997, p. 19-20).

O PNO foi objeto de ampla divulgação na sociedade portuguesa, em 2007, a partir de intensa campanha publicitária veiculada pelos meios de comunicação de massa. A campanha, difundida pelo slogan "Aprender compensa", explicita a lógica argumentativa referida no presente trabalho. Ao apresentar o Programa como essencial para "sustentar o crescimento econômico", a campanha afirmava que o "capital humano é decisivo para as empresas e para a produtividade", sublinhando a importância da capacidade de adaptação dos trabalhadores (Canário \& Rummert, 2009). Segundo a mesma publicidade, os portugueses cujas atividades laborais estavam circunscritas ao âmbito do trabalho simples (Marx, 1983), em virtude de não terem estuda- 
do, poderiam, a partir da adesão ao Programa, ocupar postos de trabalho de elevado prestígio social.

Segundo o Ministério da Educação, a campanha objetivava divulgar "as ofertas formativas destinadas a esse público-alvo, dando a conhecer a possibilidade de certificar as aprendizagens efetuadas em diversos contextos de vida" (Portugal, Ministério da Educação, 2007). Investigações preliminares permitem afirmar que, segundo a avaliação dos profissionais envolvidos no Programa, a campanha publicitária contribuiu para formar, no imaginário social, a ideia de que o Novas Oportunidades constituía uma estratégia facilitadora para a obtenção de certificações.

A ambição das metas quantitativas de atingir, até 2010, 650 mil jovens e 1 milhão de adultos, não encontrou, entretanto, a suposta correspondência no crescimento econômico do país, nem nas reais probabilidades de obtenção de um emprego, que se tornam cada vez menores, na sequência de uma tendência que já era claramente percebida pelo capital e se agudiza após a mais recente crise do capitalismo mundial. ${ }^{17}$ Em oposição, registra-se um processo já anunciado em 2004 pela Comissão do Mercado de Valores Mobiliários, que, de acordo com dados da OCDE, anunciava que "a combinação do crescimento dos custos unitários de trabalho na indústria transformadora [...] com o fraco crescimento da produtividade originaram uma perda de competitividade da economia portuguesa" (CMVM, 2004). A tendência de redução dos postos de trabalho é confirmada, em 2009, pelo Instituto Nacional de Estatística: a taxa de desemprego, no $1^{\circ}$ trimestre de 2009 , chegou a $8,9 \%$. Desses, 30,5\% correspondiam às faixas etárias mais jovens, com-

${ }^{17}$ O PNO foi alvo de avaliação divulgada e amplamente discutida na sociedade portuguesa em 2009. No volume Estudo de percepção da qualidade de serviço e satisfação, é afirmado: “O principal ganho verificado está relacionado com os aspectos ligados à majoração do Eu. Por seu lado, a componente objetiva de aquisição de conhecimentos ficou abaixo do que seria expectável. [...] É também preocupante que a qualificação proporcionada não esteja a obter no mercado de trabalho reflexos produtivos alargados" (Portugal, ANQ, 2009, p. 51). preendidas entre 15 e 34 anos (Portugal, INE, 2009). Recentemente, as previsões do desemprego estimam que, em 2010, ele ultrapasse os 10\% em Portugal, o que vem confirmando-se nos indicadores parciais que informam uma taxa de $10,6 \%$ de desemprego no primeiro trimestre (Portugal, INE, 2010).

A avaliação convergente, formulada por agentes do capital e do trabalho, bem como pelo próprio Estado, evidencia que, apesar da política de qualificação intensificada pelo atual governo, Portugal não logrou, até hoje, atingir o êxito pretendido ao nível da empregabilidade e da competitividade. Tal fato pode ser compreendido à luz da análise, apresentada anteriormente, em que procuramos evidenciar o deslocamento do cerne da problemática que atinge o mundo do trabalho - cuja gênese se situa no modelo de acumulação - para a questão educacional. Evidencia-se, assim, que a suposta solução pela via da educação de massa, sem a necessária correspondência em mudanças de caráter estrutural, constitui, sobretudo, uma política de deslocamento da responsabilidade pela obtenção de condições de sobrevivência para os indivíduos, que busca elidir as responsabilidades do Estado e as decorrências do modelo socioeconômico adotado.

Ao contrário de Portugal, que almeja a ampliação da certificação ao nível do $12^{\circ}$ ano, pressionado pelas exigências derivadas de sua integração à União Europeia, no caso do Brasil, as iniciativas empreendidas pelo governo federal, a partir de 2003, no âmbito da educação e formação profissional dos jovens e adultos, concentram-se, majoritariamente, nas ações de certificação ao nível do ensino fundamental, que corresponde ao $9^{\circ}$ ano, em Portugal. Tal fato, grosso modo, pode ser compreendido pela posição do país no cenário da divisão internacional do trabalho, que, na primeira metade da década de 2000, favoreceu a especialização produtiva “com ênfase nas exportações de produtos de menor valor agregado e reduzido conteúdo tecnológico" (Pochmann, 2008, p. 17). As marcas culturais cuja gênese se encontra no passado escravocrata, a muito elevada concentração de renda, entre outros fatores, também concorreram para a manutenção da falta de identidade - para além da função propedêutica - que 
marcou esse nível de ensino na história da educação no Brasil. Em termos legais, assim como em Portugal, tal fato só passou a ser enfrentado pelo Estado no ano de 2009, com a aprovação da obrigatoriedade do ensino médio, acompanhada, entretanto, pelas advertências governamentais sobre a morosidade que marcará seu proclamado processo de universalização. ${ }^{18}$

É importante também assinalar que as novas iniciativas, na forma de programas, como o Programa Brasil Alfabetizado, PROEJA, além do PROJOVEM, aqui abordado, vieram somar-se às ações já implementadas predominantemente no âmbito público, mas também no privado, nas esferas municipal, estadual e federal. Essa variedade de ofertas, ao contrário do que pode ser considerado com base em uma avaliação superficial, não constitui uma efetiva democratização de acesso às bases do conhecimento científico e tecnológico, correspondendo, no mais das vezes, à ampliação dos processos de "certificação vazia" (Kuenzer, 2005).

Destaca-se, ainda, o fato de que essa variedade de possibilidades, embora tenha se ampliado, está muito distante do atendimento da demanda real. Comprovam o afirmado dados divulgados pelo MEC em dezembro de 2008. Mesmo considerando o público atendido pelos novos programas e pelas redes de ensino públicas e privada, presencial e semipresencial, a cobertura é ínfima. Segundo o Ministério, da demanda potencial, só são atendidos: 9,2\% no primeiro segmento do ensino fundamental, e no segundo segmento, somente $6,7 \%$ dessa demanda estão cursando a EJA. Ao nível do ensino médio, apenas 7,4\% da demanda são alvo de atendimento escolar (Fórum EJA, 2009).

Entre as iniciativas aqui referidas, como exemplo de maior destaque, no âmbito da elevação de esco-

${ }^{18}$ A ampliação da faixa etária abrigada pela escolarização obrigatória constituiu, nos dois países, objeto de legislação específica apenas no ano de 2009. Em Portugal, a lei n. 85/2009 de 27 de agosto, estabelece o alargamento da escolaridade para 12 anos, a partir dos 5 anos de idade. No Brasil, a emenda constitucional 59, de 11 de novembro de 2009, estabelece a educação obrigatória e gratuita dos 4 aos 17 anos de idade. laridade associada à formação profissional, ao nível do ensino fundamental, destaca-se o PROJOVEM, implementado, como o PNO, em 2005. Em sua versão inicial, o PROJOVEM ${ }^{19}$ tinha por objetivo atingir, nos grandes centros urbanos, em particular nas capitais dos estados da federação, um contingente de jovens aos quais não fora assegurado o direito à educação. Em 2003, de 23,4 milhões de pessoas na faixa dos 18 aos 24 anos, apenas $34 \%$ estavam frequentando a escola; quase $5 \%$ eram analfabetos e aproximadamente $35,3 \%$ não haviam concluído sequer o ensino fundamental. ${ }^{20}$

A magnitude dos dados não se refletiu nas metas a serem atingidas. Previa-se, originalmente, atender 200 mil jovens em 2005 e, no ano de 2006, registrava-se um total de 236.997 matrículas. O PROJOVEM constituía, então, um curso de dupla vertente, oferecendo elevação de escolaridade e formação profissional de caráter inicial, além de ação comunitária, num percurso de doze meses (Rummert, 2007a). ${ }^{21}$

O Programa foi apresentado como capaz de atender às necessidades da juventude brasileira "em um momento histórico em que a tensão local/global se manifesta no mundo de maneira muito contundente: nunca houve tanta integração globalizada e, ao mesmo tempo, nunca foram tão profundos os sentimentos de desconexão e agudos os processos de exclusão"

19 O PROJOVEM certifica ao nível da $8^{\mathrm{a}}$ série do ensino fundamental. Cada aluno, como forma de incentivo, recebe um auxílio de $\mathrm{R} \$ 100,00$ por mês, desde que tenha $75 \%$ de frequência nas aulas e cumpra com as atividades programadas.

${ }^{20}$ Dados calculados pelas autoras a partir de IBGE, 2004.

${ }^{21}$ Nesse período, eram objetivos gerais: o aumento da escolaridade ao nível do ensino fundamental; a qualificação, com certificação de formação inicial e o desenvolvimento de ações comunitárias. Como objetivos específicos, pretendia-se: identificar oportunidades de trabalho e capacitação; elaborar planos para superar o quadro de destituição de direitos, denominado no documento como exclusão; desenvolver experiências de ações comunitárias e, ainda, promover a inclusão digital visando, predominantemente, à inserção produtiva (Brasil, Secretaria Geral da Presidência da República, 2006). 
(Brasil, Secretaria Geral da Presidência da República, 2006, p. 13). Na realidade, o PROJOVEM nasce sob a égide do estigma da criminalidade potencial dos jovens das frações mais destituídas de direitos da classe trabalhadora, consideradas as classes perigosas (Rummert, 2007b).

Em 2008, o PROJOVEM foi reformulado e passou a abrigar um amplo conjunto de ações para a juventude, já em curso e promovidas por diferentes esferas do governo federal, além do Programa implementado em 2005. Em seu novo formato, foi subdividido em quatro subprogramas colocados sob a responsabilidade de distintos ministérios, obedecendo a uma divisão que não se baseia, efetivamente, em fundamentações de caráter científico. Nesse quadro, chama a atenção o fato de somente o PROJOVEM Campo, que objetiva oferecer a jovens da agricultura familiar, de 18 a 29 anos, a conclusão do ensino fundamental em regime de alternância com os ciclos agrícolas, estar diretamente vinculado ao Ministério da Educação. A destacar também o fato de o PROJOVEM Adolescente - destinado aos jovens de 15 a 17 anos em situação de risco social, independentemente da renda familiar, ou que sejam pertencentes ao Programa Bolsa Família - ser coordenado pelo Ministério do Desenvolvimento Social e Combate à Fome, constituindo, segundo expressivo grupo de especialistas, um retocesso que retoma uma vertente de vinculação entre a educação e a assistência social, que se supunha praticamente superada no país.

O PROJOVEM original, tendo por base avaliações parciais do Sistema de Monitoramento e Avaliação, transforma-se no PROJOVEM Urbano, ${ }^{22}$ ampliado para 18 meses distribuídos em três ciclos de estudos, ao longo dos quais os alunos são subme-

${ }^{22}$ As informações sobre histórico, implementação, detalhamento da organização curricular etc. podem ser encontradas no Projeto Pedagógico Integrado - PPI PROJOVEM Urbano (Brasil, Secretaria Geral da Presidência da República, 2008a) e em Orientações gerais para a elaboração do Plano de Implementação do ProJovem Urbano (Brasil, Secretaria Geral da Presidência da República, 2008b). tidos a três exames nacionais. É também ampliada a faixa etária de atendimento para os 29 anos. São mantidos os objetivos gerais e a estrutura em três eixos: formação geral, qualificação profissional e ação comunitária, bem como bolsa mensal de $\mathrm{R} \$ 100,00$. As novas metas propostas para essa vertente do Programa situavam-se, em 2008, em 250 mil vagas, pretendendo-se atender um total de 900 mil jovens até o final do ano de $2010,{ }^{23}$ o que constitui meta modesta, se considerarmos a amplitude da demanda, como já referido. Assim como o PNO, alvo de intensa campanha publicitária, os potenciais alunos eram chamados pelo slogan: "Para quem tem a vida a ganhar e nenhum tempo a perder".

O PROJOVEM Trabalhador, vinculado ao Ministério do Trabalho e Emprego, volta-se para jovens desempregados com idades entre 18 e 29 anos, que sejam membros de famílias com rendimentos per capita iguais ou inferiores à metade do salário mínimo $\mathrm{e}$ objetiva "Preparar o jovem para o mercado de trabalho e para ocupações alternativas geradoras de rendimento" (Brasil, Ministério do Trabalho e Emprego, 2008c). Esse objetivo enfatiza o autoemprego e o empreendedorismo como soluções para o desemprego.

Sua organização pedagógica distribui-se em cem horas destinadas à Qualificação Social ${ }^{24}$ e 250 horas

${ }^{23}$ Ao contrário do PNO, a avaliação do ProJovem, com circulação restrita, é divulgada com expressiva defasagem temporal. Em abril de 2010, foi divulgada a avaliação relativa a 2007, na qual é evidenciado o fato de que o índice de evasão estava em torno dos 57\%. Como fatores decisivos para o elevado índice, já referidos (Rummert, 2007a e 2007b), destacam-se: o atraso no pagamento das bolsas, bem como as diferentes insuficiências relativas às aulas de informática (Brasil/ Coordenação Nacional do ProJovem, 2010).

${ }^{24} \mathrm{O}$ conteúdo programático da Qualificação Social inclui: “a) inclusão digital - 40 horas/aula; b) valores humanos, ética e cidadania - 10 horas/aula; c) educação ambiental, higiene pessoal, promoção da qualidade de vida - 10 horas/aula; d) noções de direitos trabalhistas, formação de cooperativas, prevenção de acidentes de trabalho - 20 horas/aula; e e) estímulo e apoio à elevação da escolaridade: 20 horas/aula" (MTE, 2009). 
destinadas à qualificação profissional de nível inicial, com duração total de seis meses. Nos limites deste artigo, restringimo-nos a questionar o grau de efetivo compromisso com a inserção dos jovens, a partir do que nos é apresentado pelo Ministério, quando estabelece que os "entes executores" devem assumir, apenas, a "meta mínima obrigatória de $30 \%$ de inserção de jovens no mundo do trabalho"25 (Brasil, Ministério do Trabalho e Emprego, 2008d). No mesmo documento, afirma-se ainda que a comprovação de tal inserção deverá ser feita por diferentes vias, entre as quais a apresentação da "cópia legível do contrato celebrado com a empresa ou órgão onde o jovem for inserido", ou a mera comprovação de aquisição, pelo jovem, de equipamentos e matéria-prima por meio de uma fatura e/ou de um termo de doação deles (idem).

Na realidade, a lógica que permeia o Programa aqui abordado, no que concerne à formação geral e à qualificação profissional centrada no trabalho simples, parece convergir com a perspectiva do Banco Mundial, ao defender o empreendedorismo como alternativa à pobreza, valorizando sobremaneira a formação de microempresários, assim compreendidos: "Centenas de milhões de pessoas de baixa renda [que] ganham a vida como microempresários agricultores, vendedores ambulantes, empregados domésticos e uma grande variedade de outras ocupações, principalmente na economia informal" (Banco Mundial, 2005, p. 9).

Em oposição à situação portuguesa, o Brasil parece viver uma fase de crescimento econômico, com leve redução do desemprego, que, no último mês de abril, registrou a menor taxa para esse mês, desde o início da elaboração da série histórica, em 2002, caindo para 7,3\%, conforme dados obtidos no IBGE (Reuters Brasil, 2010). Tal redução, entretanto, deve ser avaliada com reservas, em face da relação verificada no país entre o desemprego conjuntural e o estrutural. Segundo Pochmann, o desemprego conjuntural

${ }^{25}$ A distribuição das metas em cada estado brasileiro para o ProJovem Trabalhador, no período de 2008 a 2011, está disponível em Brasil, Ministério do Trabalho e Emprego (2008e). "pode ser revertido mais facilmente com a elevação do ritmo de crescimento das atividades produtivas"; já o desemprego estrutural "requer mudanças importantes no interior do padrão de relacionamento com a globalização" (2008, p. 35), o que não podemos apontar como padrão do atual modelo socioeconômico do país. Como afirma Alves, ao analisar os casos de Portugal e da França, o Brasil também incorpora a "crença no papel milagroso da educação" e adota "uma política voluntarista que, ao não questionar o atual modelo de acumulação capitalista, acredita que o problema do desemprego juvenil é um problema de falta de qualificação e que pode ser resolvido no quadro do território nacional" (Alves, 2009, p. 127).

\section{Considerações finais}

As iniciativas aqui analisadas parecem concorrer, de forma significativa, para que jovens e adultos, executores predominatemente de trabalho simples particularmente no caso brasileiro -, sobrevivam sem criar tensões sociais indesejáveis ao instituído. Assim, o deslocamento da discussão dos efeitos do atual modelo de acumulação do campo político-econômico para a esfera individual contribui significativamente para que a hegemonia da lógica dominante se difunda em ambas as sociedades com o intenso "consentimento ativo dos governados" (Gramsci, 1999).

É a existência de sólidas relações entre os paradigmas produtivos e o projeto societário que possibilita a construção de um novo bloco histórico (idem), constituído por uma direção econômica e política que determina a unidade intelectual e comportamental, cognitiva e socioafetiva, a ser incorporada pela totalidade social. Esse processo, porém, não elimina as contradições inerentes a todos os projetos societários característicos de um país ou de um bloco político-econômico. É a impossibilidade de suprimir as contradições e as tensões sociais delas decorrentes que exige a permanente formulação de estratégias de controle social.

Os programas aqui analisados se inscrevem, como procuramos explicitar, nesse quadro. Tratase sobretudo de formar uma concepção de mundo 
consentânea com as características do atual cenário internacional, em que ambos os países se inscrevem, sob formas particulares de subalternidade. Nesse quadro, a visão economicista constitui o determinante fundamental das propostas formuladas. Não porque elas formem efetivamente quadros qualificados para a inserção no núcleo orgânico do processo produtivo, mas porque visam criar vias de escape para aqueles que não serão efetivamente incorporados, mas que precisam ser mantidos sob controle e conformados, de modo que não venham a se tornar geradores de instabilidade social.

Tanto o PNO quanto o PROJOVEM constituem parte de uma ampla estratégia de engenharia social que incorpora, em diferentes níveis e ofertas de educação e formação, um contingente populacional que deve, mesmo perifericamente, estar coadunado com seu tempo. Ou seja, é necessário que se tornem indivíduos flexíveis, adaptáveis, capazes de resolver de forma criativa, com seus recursos pessoais, os problemas atuais e futuros que a precarização da existência lhes impõe cotidianamente na nova sociedade do conhecimento.

$\mathrm{Na}$ realidade, para o público-alvo dos dois Programas, não é necessário ir mais além. Apesar do anunciado, ambos os países continuam a não ser senhores dos meios materiais e das condições políticas para construir uma ampla e sólida base científicotecnológica que permitam definir as características e os rumos das suas estruturas produtivas e superar as condições de subordinação em que se situam no quadro da divisão internacional do trabalho e da produção do conhecimento.

\section{Referências bibliográficas}

ALVES, Natália. Jovens pouco escolarizados e políticas activas de emprego. In: RUMMERT, Sonia Maria; CANÁRIO, Rui; FRIGOTTO, Gaudêncio. Politicas de formação de jovens e adultos no Brasil e em Portugal. Niterói: EdUFF, 2009. p. 113-132.

Juventudes e inserção profissional. Lisboa: Educa/ UI\&DCE, 2008.

ARRIGHI, Giovanni. A ilusão do desenvolvimento. 6. ed. Petrópolis: Vozes, 1997.
BANCO MUNDIAL. Relatório sobre o desenvolvimento mundial 2005. Um melhor clima de investimentos para todos. 2005. Disponível em: <www.bancomundial.org.br/index.php/content/ view_folder/2129.html >. Acesso em: set. 2008.

BRASIL, IBGE. Anuário Estatístico do Brasil de 1940. Rio de Janeiro: IBGE, 1941.

. Anuário Estatístico do Brasil de 1960. Rio de Janeiro: IBGE, 1962.

. IBGE Teen. Analfabetismo: evolução no mundo, 2009a.

Disponível em: <http://www.ibge.gov.br/ibgeteen/datas/alfabetizacao/evolucao.html>. Acesso em: abr. 2010.

. Pesquisa Nacional por Amostragem de Domicílios - 2003.

Rio de Janeiro: IBGE, 2004.

Séries estatísticas e séries históricas. 2009b. Disponível em: http://www.ibge.gov.br/series_estatisticas/exibedados. php?idnivel=BR\&idserie=ECE303. Acesso em: abr. 2010.

BRASIL. Ministério da Educação/SETEC. PROEJA. 2009. Disponível em: <http://lce.mec.gov.br/index.php?option=com_cont ent\&view=article\&id=12288:programa-nacional-de-integracaoda-educacao-profissional-com-a-educacao-basica-na-modalidadede-educacao-de-jovens-e-adultos-proeja\&catid=259:proeja\&Itemid $=562>$. Acesso em: set.2009 [atualmente ainda disponível em PROEJA - IFECT - Campus Vitória da Conquista: $<$ http:// eusouproeja.blogspot.com>. Acesso em: 20 maio 2010].

. PROEJA. 2010. Disponível em: <http://portal.mec.gov. br/index.php?option=com_content $\&$ view $=$ article $\&$ id=12288:pro grama-nacional-de-integracao-da-educacao-profissional-com-aeducacao-basica-na-modalidade-de-educacao-de-jovens-e-adultosproeja\&catid=259:proeja- $\&$ Itemid=562> . Acesso em: mar. 2010 . BRASIL. Ministério do Trabalho e Emprego. PROJOVEM Trabalhador. 2008c. Disponível em:< http://www.mte.gov.br/ProJovem/ default.asp>. Acesso em: abr. 2010.

ProJovem Trabalhador - Juventude cidadã. Termo de referência. 2008d. Disponível em: <http://www.mte.gov.br/ legislacao/portarias/2008/p_20082711_991_anexoI.pdf>. Acesso em: jan. 2009.

. Distribuição das metas estaduais - PROJOVEM Trabalhador-2008-2011. 2008e. Disponível em: <http://www.mte.gov. br/politicas_juventude/ProJovem_meta_proposta.pdf $>$. Acesso em: mar. 2009

Portaria n. 2.043, de 22 de outubro de 2009.

BRASIL. Presidência da República. Casa Civil. Lei n. 11.692, de 10 de junho de 2008. 
Emenda Constitucional 59, de 11 de novembro de 2009. BRASIL. Secretaria Geral da Presidência da República. Coordenação Nacional do PROJOVEM. Programa Nacional de Inclusão de Jovens. Educação, Qualificação e Ação Comunitária. Brasília, março de 2005. Disponível em: <http://www.aracati.org.br/portal/ pdfs/13_Biblioteca/Documentos/ProJovemf $>$. Acesso em: jan. 2006.

Projeto do Programa PROJOVEM. Brasília: Programa Nacional de Inclusão de Jovens, 2006.

. Projeto Pedagógico Integrado-PPI PROJOVEM Urbano. Brasília: Programa Nacional de Inclusão de Jovens, 2008a.

Orientações gerais para a elaboração do Plano de Implementação do PROJOVEM Urbano. Brasília: Programa Nacional de Inclusão de Jovens,2008b.

Relatório Parcial de Avaliação do PROJOVEM. Brasília, 2010.

CANÁRIO, Rui (2001). A “aprendizagem ao longo da vida". Análise crítica de um conceito e de uma política. In:

(Org.). Formação em situações de trabalho. Porto: Porto Editora, 2001. p. 191-207.

Educação de adultos. Um campo e uma problemática. Lisboa: Educa, 1999.

Formação e adquiridos experienciais: entre a pessoa e o indivíduo. In: FIGARI; RODRIGES; ALVES; VALOIS (Org.). Avaliação de competências e aprendizagens experienciais. Saberes, modelos e métodos. Lisboa: Educa, 2004. p. 35-45.

CANÁRIO, Rui; RUMMERT, Sonia Maria. Educação de Jovens e Adultos trabalhadores no Brasil e em Portugal. Escritos preliminares. In: SOUZA, Donaldo; MARTINEZ, Silvia. Educação comparada: rotas de além-mar. São Paulo: Xamã, 2009. v.1, p. 355-371.

CANDEIAS, António; SIMÕES, Eduarda. Alfabetização e escola em Portugal no século XX: Censos Nacionais e Estudos de caso. Análise Psicológica, 1 (XVII), p. 163-194, 1999.

V CONFITEA(Conferência Internacional sobre Educação de Adultos). Declaração de Hamburgo: agenda para o futuro. 1999. Brasília: SESI/UNESCO. Disponível em: $<$ http://www.dominiopublico. gov.br/download/texto/ue000006.pdf>. Acesso em: abr. 2009.

CNI (Confederação Nacional da Indústria). Educação para a nova indústria: uma ação para o desenvolvimento sustentável do Brasil. Brasília: CNI, 2007.

COMISSÃO DO MERCADO DE VALORES MOBILIÁRIOS (CMVM). Relatório sobre a Situação Geral dos Mercados de Va- lores Mobiliários. 2004. Disponível em: <http://www.cmvm.pt/NR/ rdonlyres/00EF901A-E9B4-4900-98DC-9A57A4B28C6C/2462/ RA2004_Cap12.pdf $>$. Acesso em: abr. 2010.

COMITÊ EUROPEU PARA A COESÃO SOCIAL. Uma nova estratégia para a coesão social. 2004. UE: MTSS/Conselho da Europa. Disponível em: <catesoc.gep.mtss.gov.pt/plinkres.asp>. Acesso em: jan. 2008.

CONSELHO EUROPEU DE LISBOA. 2000. Disponível em: $<$ http://indest.ine.pt/IETree.asp > . Acesso em: abr. 2010.

ESTRELA, Elsa; TEODORO, António. As políticas curriculares em Portugal (1995-2007). Agendas globais e e reconfigurações regionais e nacionais. Trabalho apresentado no III Colóquio Internacional de Políticas Curriculares, Universidade Federal da Paraíba, João Pessoa, Brasil, 12-14 novembro 2007. Disponível em: $<$ http:// cyted.riaipe.net/index.php?option $=$ com_docman\&task $=$ cat_view \&Itemid $=26 \&$ gid $=29 \&$ orderby $=$ dmdatecounter\&ascdesc $=$ DES C>. Acesso em: abr. 2009.

FÓRUM EJA. Cobertura - Educação de Jovens e Adultos. 2009. Disponível em: <http://forumeja.org.br/files/agenda. ppt\#263,7,Slide 7>. Acesso em: nov. 2009.

GONÇALVES, Reinaldo. A herança e a ruptura: cem anos de história econômica e propostas para mudar o Brasil. Rio de Janeiro: Garamond, 2003.

GRAMSCI, Antonio. Cadernos do Cárcere. Introdução ao estudo da Filosofia. A filosofia de Benedetto Croce. v. 1. Tradução de Carlos Nelson Coutinho. Rio de Janeiro: Civilização Brasileira, 1999.

. Cadernos do cárcere. Os intelectuais. O princípio educativo. Jornalismo. v. 2. Tradução de Carlos Nelson Coutinho. Rio de Janeiro: Civilização Brasileira, 2000.

. Maquiavel, a Política e o Estado Moderno. Tradução de Carlos Nelson Coutinho. Rio de Janeiro: Civilização Brasileira, 1988.

HARVEY, David. A condição pós-moderna. São Paulo: Loyola, 1992.

IOCHPE, Evelin. Terceiro setor: o desafio da conceituação. 1998. Disponível em: <http://www.flochpe.org.br. Acesso em: 3 abr. 2005.

KUENZER, Acácia. Exclusão includente e inclusão excludente: a nova forma de dualidade estrutural que objetiva as novas relações entre educação e trabalho. In: LOMBARDI, José; SAVIANI, Dermeval; SANFELICE, José (Org.). Capitalismo, trabalho e educação. 3. ed. São Paulo: Autores Associados; HISTEDBR, 2005. 
LEHER, Roberto. Brazilian Education, Dependent Capitalism and the World Bank. In: HILL, David; KUMAR, Ravi (Org.). Global Neoliberalism and Education and its consequences. Nova York: Routledge, 2008, p. 125-148.

LIMA, Licínio. Políticas de educação de adultos: da (não) reforma às decisões políticas pós-reformistas. In: (Org.). Educação de adultos - Fórum III. Braga: Universidade do Minho/Unidade de Educação de Adultos, 2004. p. 19-44.

MARTINHO, Palomanes; PINTO, Antonio Costa. O corporativismo em português: Estado, política e sociedade no Salazarismo e no Varguismo. Rio de Janeiro: Civilização Brasileira, 2007.

MARX, Karl. O Capital: Crítica da economia política.O processo global da produção capitalista. São Paulo: Abril Cultural,1983, v. 3. MENDONÇA, Sonia; FONTES, Virgínia. História do Brasil recente - 1964-1980. 2. ed. São Paulo: Ática,1991.

POCHMANN, Márcio. O emprego no desenvolvimento da nação. São Paulo: Boitempo, 2008.

PORTUGAL. Agência Nacional de Qualificação (ANQ). Iniciativa Novas Oportunidades. Primeiros Estudos de Avaliação Externa. v. 5. Qualidade e satisfação. Lisboa: ANQ, 2009.

PORTUGAL. Assembleia da República. Lei 85/2009, de 27 de agosto.

PORTUGAL. INE. Censo de 1991. Lisboa, INE, 1991. Censo de 2001. Lisboa, INE,2001.

Taxa de desemprego 1998 - percentual. 2010. Disponível em: <http://www.ine.pt/xportal/xmain?xpid=INE\&xpgid=ine_i ndicadores $\&$ indOcorrCod $=0000593 \&$ selTab $=$ tab0 $>$. Acesso em: maio 2010 .

PORTUGAL. Ministérios da Administração Interna, do Trabalho e Coesão Social e da Educação. 2006. Disponível em: <http://www. candidaturas.gepe.min-edu.pt/helios/aspx/download.aspx?id $>$. Acesso em: maio 2009.

PORTUGAL. Ministério da Educação. Aprender compensa. 2007. Disponível em: <http://www.min-edu.pt/np3/491.html>. Acesso em: set. 2007.

PORTUGAL. Ministério da Educação. Novas Oportunidades: Aprender compensa. Vídeo de divulgação. Disponível em: $<$ http:// www.min-edu.pt/np3/491.html>. Acesso em: mar. 2010.

PORTUGAL. Ministério da Educação/Direção Geral de Inovação e Desenvolvimento Curricular (dez. 2007). Disponível em: $<$ www. mai.gov.pt/data/areas_accao/prot_e_learning.doc $>$. Acesso em: maio 2010.

PORTUGAL. Ministério da Educação/GIASE. Sistema educati- vo português. Situação e tendências - 1990-2000. Lisboa: ME/ GIASE, 2004.

PORTUGAL. Novas oportunidades. 2007. Disponível em: <http:// www.novasoportunidades.gov.pt/np4/39.html>. Acesso em: set. 2007.

REUTERS Brasil. Desemprego no Brasil tem menor abril desde 2002 a 7,3\%. 2010. Disponível em: <http://br.reuters.com/article/ domesticNews/idBRSPE64Q06D20100527>. Acesso em: maio 2010 .

RUMMERT, Sonia Maria. Aspirações, interesses e identidade dos trabalhadores: elementos essenciais à construção da hegemonia. Revista eletrônica Trabalho necessário, UFF/Programa de PósGraduação/NEDDATE, v. 2, 2004.

. A educação de jovens e adultos trabalhadores. O "novo" que reitera antiga destituição de direitos. In: RUMMERT, S. M. Gramsci, trabalho e educação: jovens e adultos pouco escolarizados no Brasil actual. Cadernos Sísifo 4. Lisboa: Educa/Universidade de Lisboa, 2007a.

. Educação e identidade dos trabalhadores: as concepções do capital e do trabalho. São Paulo: Xamã / Niterói: Intertexto, 2000 .

. Intervenções comunitárias como controle social na sociedade brasileira. O caso do PROJOVEM. In: CONGRESSO INTERNACIONAL DE INTERVENÇÃO COM CRIANÇAS, JOVENS E FAMÍLIAS, 1.,2007, Braga. Intervenção com Crianças, Jovens e Famílias - I Congresso Internacional. Braga: Universidade do Minho, 2007b.

SANTOS, Boaventura Sousa. O Estado e a sociedade em Portugal (1974-1988). Porto: Afrontamento, 1990.

SILVA JR., João dos Reis. A planetarização da cultura do capital e as reformas da educação superior no Brasil. Trabalho \& Educação, UFMG, v. 15, p. 10-31, 2006.

SILVA, Manuela. Crescimento econômico e pobreza em Portugal (1950-1974). Análise Social, v. XVIII (72-73-74), 1982.

SIQUEIRA, Ângela. Multilateral agencies and their policy proposals for education: Are they contributing to reduce the knowledge gap in the world? Eric Database, EUA, v. ED, n. 472147,2003 . p. 1-37.

. A regulamentação do enfoque comercial via OMC/GATS. Revista Brasileira de Educação, v. 26, p. 145-156. 2004.

STOER, Stephen; ARAÚJO, Helena. Escola e aprendizagem para o trabalho num pais da semiperiferia europeia. Lisboa: Escher, 1992. 
TEODORO, António. Organizações internacionais e políticas educativas nacionais: a emergência de novas formas de regulação transnacional, ou uma globalização de baixa intensidade. In: STOER, Stephen; CORTESÃO, Luiza; CORREIA, José (Org). Transnacionalização da educação: da crise da educação à "educação" da crise. Porto: Edições Afrontamento, 2001.

THE WORLD BANK/The International Bank for Reconstruction and Development. 2000. Higher Education in Developing Countries. Peril and Promise. Disponível em: $<$ http://www.tfhe.net/ report/downloads/report/whole.pdf $>$. Acesso em: dez. 2008.

UNIÃO EUROPEIA. Europa - Glossário. Disponível em: <http:// europa.eu/scadplus/glossary/open_method_coordination_pt.htm $>$. Acesso em: mar. 2010.

SONIA MARIA RUMMERT, doutora em ciências humanas educação, é professora do Programa de Pós-Graduação em Educação (Mestrado e Doutorado) da Universidade Federal Fluminense (UFF), atuando no Campo de Confluência Trabalho e Educação, no qual é membro do Núcleo de Estudos, Documentação e Dados sobre Trabalho e Educação (NEDDATE-UFF). Pesquisadora do Conselho Nacional de Desenvolvimento Científico e Tecnológico (CNPq), coordena atualmente o Projeto de Pesquisa "Educação de jovens e adultos trabalhadores no Brasil e em Portugal. Estudos comparados sobre novas expressões da dualidade estrutural no padrão de acumulação flexível”. É coordenadora brasileira do Projeto
"Trabalho e formação de jovens e adultos trabalhadores com baixa escolarização. Políticas e práticas no Brasil e em Portugal”, financiado pela Coordenação de Aperfeiçoamento de Pessoal de Nível Superior (CAPES), no Brasil, e pela Fundação para a Ciência e a Tecnologia (FCT), em - Portugal. E-mail: rummert@uol.com.br

NATÁLIAALVES, doutora em sociologia da educação pela Universidade de Lisboa, é professora do Instituto de Educação da mesma universidade e investigadora da Unidade de I\&D de Ciências da Educação e da FCT. Integra também a equipe de Coordenação dos Cursos de Formação Avançada (mestrado e doutorado) em Ciências da Educação - área de formação de adultos da mesma universidade. Leciona e investiga nas áreas da sociologia da educação e da formação de adultos. Entre os temas de pesquisa que tem vindo a privilegiar nos últimos anos, salientam-se a inserção profissional dos diplomados do ensino superior, as políticas públicas de educação-formação para jovens e adultos pouco escolarizados e a relação entre o sistema de educação/formação e o mercado de trabalho. É coordenadora do Projeto de Pesquisa EDUQUAL Novas Oportunidades: educação e qualificação, financiado pela FCT. E-mail: nalves@ie.u.pt 
Sonia Maria Rummert e Natália Alves

Jovens e adultos trabalhadores

pouco escolarizados no Brasil e em 


\section{Portugal: alvos da mesma lógica de conformidade}

$\mathrm{O}$ artigo analisa medidas referentes às políticas educacionais dirigidas $\mathrm{a}$ jovens e adultos pouco escolarizados, no Brasil e em Portugal, que, a despeito de suas diferenças, apresentam similaridades devidas a sua posição no cenário internacional, assim como se mostram receptivas às determinações emanadas por organizações supranacionais. Comum a essas organizações é a defesa de uma concepção instrumental de educação para a empregabilidade, produtividade, competitividade e coesão social. Os governos dos dois países aderiram às teses de que sua posição na divisão internacional do trabalho é resultado do baixo nível de qualificação da classe trabalhadora. A análise compreende os Programas Novas Oportunidades, em Portugal, e PROJOVEM, no Brasil, e destaca que ambos contribuem para aumentar a subordinação funcional das políticas educacionais aos interesses econômicos e para reforçar a conformidade ideológica da classe trabalhadora nos dois países.

Palavras-chave: educação de jovens e adultos; políticas públicas; trabalho e educação; estudos comparados Brasil e Portugal

\section{Young and adult workers with little schooling in Brazil and} Portugal; targets of the same logic of conformity

The article analyzes measures that refer to educational policy aimed at young people and adults with little schooling in Brazil and Portugal, which, despite its differences, presents similarities due to its position on the international stage, as well as demonstrating its receptiveness to the determinations emanating from supranational organizations. These organizations have in common the defence of an instrumental conception of education for employability, productivity, competitiveness and social cohesion. The governments of both countries have adhered to the proposition that their position in the international division of work is the result of the low level of qualification of the working class. The analysis covers the New Opportunities Programme (Programa Novas Oportunidades) in Portugal and the ProJovem Programme in Brazil, and indicates that both contribute to increase the functional subordination of educational policies to economic interests and to reinforce the ideological conformity of the working class in both countries.

Key words: youth and adult education; public policy; work and education; comparative studies in Brazil and Portugal.

\section{Jóvenes y adultos trabajadores poco escolarizados en Brasil y en Portugal: albos de la misma lógica de conformidad}

El artículo analiza medidas que hacen referencia a las políticas de la educación que son dirigidas a jóvenes $y$ adultos poco escolarizados, en Brasil y en Portugal, que, a pesar de sus diferencias, presentan analogías debidas a su posición en el escenario internacional, así como se muestran receptivas a las determinaciones emanadas por organizaciones supranacionales. Común a esas organizaciones es la defensa de una concepción instrumental de educación para la labor, productividad, competitividad y cohesión social. Los gobiernos de los dos países adhirieron a las tesis de que su posición en la división internacional del trabajo es resultado del bajo nivel de calificación de la clase trabajadora. El análisis comprende a los Programas Nuevas Oportunidades, en Portugal, y Pro Joven, en Brasil, y destaca que ambos contribuyen para aumentar la subordinación funcional de las políticas de educación a los intereses económicos y para reforzar la conformidad ideológica de la clase trabajadora en los dos países.

Palabras clave: educación de jóvenes y adultos; politicas públicas; trabajo y educación; estudios comparados de Brasil y Portugal 